\title{
COMMENTARY
}

\section{The dilemma of good clinical practice in the study of compromised standards of care}

\author{
Yechiel M Barilan* \\ See related research by Lieberman et al., http://ccforum.com/content/14/2/R48
}

\begin{abstract}
Four ethical issues loom over the study by Lieberman and colleagues - the absence of informed consent, the study being non-interventional in situations that typically call for life-saving interventions, the bias involved in doctors that study their own problematic practice and monopoly over intensive care unit triage, and ageism. We learn that the Israeli doctors in this study never make no-treatment decisions regarding patients in need of mechanical ventilation. They are complicit with botched standards of care for these patients, however, accepting without much doubt an ethos of scarce resources and poor managerial habits. The main two practical lessons to be taken from this study are that, for patients in need of mechanical ventilation, compromised care is better than a policy of intubation only when the intensive care unit is available, and that vigorous efforts are needed in order to extirpate ageism.
\end{abstract}

The biomedical community has established the standards of good clinical practice as the cornerstone of medical research on humans [1]. What are the standards for studying practices that overtly and intentionally fall short of good practice and are clearly discriminatory against the aged?

I find four ethical problems in the study on ventilated patients outside the intensive care unit (ICU) [2]. First, the local Institutional Review Board waived the requirement for informed consent. Had this been an interventional study, omission of informed consent would have been unthinkable. But, unfortunately, in that hospital, and in many others, these patients would have been sent anyway to a medical floor. In some other countries, they

*Correspondence: YMBarilan@Gmail.com

Department of Medical Education, Sackler Faculty of Medicine, Tel Aviv University, Tel Aviv, 69978 Israel would not have been ventilated at all unless an ICU bed was secured for them in advance. This study at least offered care and follow up by an ICU representative.

This brings forth the second ethical concern - the study being non-interventional. The fundamental difference between the ICU and a regular hospital floor lies in the capacity to monitor and to react. Is it not likely that when an ICU person collects all sorts of data on the participants, issues come to attention - such as wrong ventilator settings, a need for a different drug, and so forth? Intervention is incompatible with the methodology of the study; non-intervention is grossly immoral. Moreover, since ICU beds might become available and patients might deteriorate, ventilated patients who cannot be admitted to the ICU on the day of hospitalization deserve reassessment for admittance later on. Interestingly, no study patient was transferred from the medical floor to the ICU.

A third problem is related to the fact that in Israel, as well as in many other places, the decision of whether to admit a patient to the ICU is solely in the hands of ICU doctors. It follows that this research was conducted in order to evaluate the safety of gatekeeping by the very people who serve as the sole gatekeepers. I wish the ethics committee of Soroka Hospital had set some provisory guidelines for triage and for care of ventilated patients in the medical floors prior to that hospital's Institutional Review Board's endorsement of this noninterventional study.

The authors themselves testify to their deviation from established ethical norms: the recommendation that 'chronological age per se is not a relevant criterion for hospitalization in an ICU' [2] was not substantiated in the present study population.

What the authors actually say is that the ICU team in their hospital violates professional ethical guidelines protecting a vulnerable population, without any sort of reflection or policy endorsement. This statement is bewildering.

This statement is interesting too. A study conducted in the United Kingdom found that $12 \%$ of ICU patients could be cared for in a regular ward and 53\% of ward 
patients were better suited for ICU care. Age did not correlate with misplacement. Healthcare expenditure, which is an explicit concern in the article, did not correlate with availability and accessibility of intensive care services [3]. A meta-analysis of numerous clinical publications from all over the world has found age to be a factor in the triage of patients for critical care [4]. The number of ICU beds per capita varies substantially from one place to another, and a low bed/population ratio correlates with increased inhospital mortality overall [5]. Perhaps ageism rears its head when the ratio of ICU beds to population is low, as is the case in Israel. Deliberate rationing of scarce health resources on the basis of age is highly controversial. Like any other form of rationing, it depends on open deliberation for justification and legitimization [6,7], and not on inconclusive evidence and a motivation to save money.

A serious confounding factor in the whole discourse on the allocation of intensive care is lack of clarity regarding the prognosis of ventilated patients. For some, ICU care is plainly futile - but legal and psychosocial issues do not allow doctors to disconnect. It is justified not to place such patients in the ICU. A second group of patients is also sent to the regular floor, however, not because they do not need intensive care but because the person responsible for the ICU does not have a bed for them. In the absence of conceptual differentiation of patients who need ICU care from those for whom such care is futile, little may be said about the overall outcome in terms of mortality.

We are not surprised to learn that mortality was higher outside the ICU. Those who are accustomed to seeing ventilated patients on the medical floors are not surprised to learn that more than one-quarter of them survived despite non-ICU standards of care.
Doctors who avoid intubation of patients that have no chance of entry into the ICU may reconsider this policy. In my eyes, this is the most important lesson to take from this publication.

My second take-home message is that ageism is still prevalent in healthcare and clinical research. Policymakers should deliberate more openly the role of age in distributive justice in healthcare, while boosting awareness of existing ethical guidelines and of every doctor's commitment to protect the vulnerable.

\section{Abbreviations}

ICU, intensive care unit.

\section{Competing interests}

The author declares that he has no competing interests.

Published: 15 July 2010

\section{References}

1. ICH Topic E 6 (R1) Guideline for Good Clinical Practice [http://www.ema. europa.eu/pdfs/human/ich/013595en.pdf]

2. Lieberman D, Nachshon L, Miloslavsky O, Dvorkin V, Shimoni A, Zelinger J, Friger M, Lieberman D: Elderly patients undergoing mechanical ventilation in and out of intensive care units: a comparative, prospective study of 641 ventilations. Crit Care 2010, 14:R48.

3. Hubbard RE, Lyons RA, Woodhouse KW, Hillier SL, Warham K, Ferguson B, Major E: Absence of ageism in the access to critical care: a cross sectional study. Age Ageism 2002, 32:382-387.

4. Sinuff T, Kahanmoui K, Cook DJ, Luce J, Levy M: Rationing critical care beds: a systematic review. Crit Care Med 2004, 32:1588-1597.

5. Wunsch H, Angus DC, Harrison DA, Collange O, Fowler R, Hoste EA, de Keizer NF, Kersten A, Linde-Zwirble WT, Sandiumenge A, Rowan KM: Variation in critical care services across North America and Western Europe. Crit Care Med 2008, 36:2787-2793.

6. Fleck L: Just Caring: Healthcare Rationing and Democratic Deliberation. Oxford: Oxford University Press; 2009.

7. Barilan YM, Brusa M: Triangular reflective equilibrium and bioethical deliberation. Bioethics 2009. [Epub ahead of print]

\section{doi:10.1186/cc9073}

Cite this article as: Barilan YM: The dilemma of good clinical practice in the study of compromised standards of care. Critical Care 2010, 14:176. 